\title{
As Needed
}

National Cancer Institute

\section{Source}

National Cancer Institute. As Needed. NCI Thesaurus. Code C64499.

As needed, usually referring to the timing of the administration of a treatment or medication. 